\title{
CENTERING SOCIAL JUSTICE \\ IN THE SCHOLARSHIP OF \\ COMMUNITY ENGAGEMENT
}

\author{
Tania D. Mitchell and Tabbye Chavous
}

Our partnership with MJCSL to produce this special issue was based on the premise that exploring the roles and promise of higher education in working toward social justice was a critical imperative. The past year has made the urgency of this issue even more clear. When we began the work to plan this issue-sending out the call for proposals, thinking through the timeline to publication - we had not yet heard of the novel coronavirus. As we were all trying to navigate the COVID-19 global pandemic, the disproportionate impacts of the pandemic created a stark picture of economic stratification, the disparities in health care access, and the racial realities of both. As institutions, engagement centers, and instructors were thinking about how community engagement work might need to change to be responsive to the COVID-19 pandemic, the inequities laid bare made clear the need to center social justice in this work. Then, the multiple killings of unarmed Black Americans-Breonna Taylor, Ahmaud Arbery, Elijah McClain, Rayshard Brooks, Tony McDade, George Floyd, to name only a few-due to the actions of law enforcement, inspired a series of social protests but also commitments from higher education leaders to move their institutions toward racial equity, another signal that community engagement should center social justice. The deaths, in the United States, of over 600,000 from COVID-19 (Allen et al., 2021); the loss of more than a dozen Black transwomen in 2021 (Yurcaba, 2021); the increase in the food insecurity of more than 40 million people (Feeding America, 2021); an insurrection attempt on the U.S. Capitol led by individuals with ties to anti-Semitic and white nationalist movements; efforts in 43 states to reduce access to voting in ways that would disproportionately affect Black, Indigenous, and People of Color (BIPOC) communities; increased incidents of violence targeting Asian and Asian American communities, including the murders, in March of 2021, of six women of Asian descent in a mass shooting at three spas in Atlanta that took eight lives in total-we are living in a moment that requires attention to and action for social justice.

\section{How might higher education community engagement best contribute to that need?}

Many are now grappling more deeply with how institutions of higher education have been and continue to be complicit in the colonialism and white supremacy that fuel the aforementioned oppressive structures and acts; 
indeed, this grappling must also include the field of service-learning and community engagement (SLCE). As such, we view this special issue as an opportunity to showcase work that illustrates and reflects the positive impacts, promise, and continued challenges of higher education community engagement, in ways that prompt and support community-engaged scholars and practitioners toward more just and even more impactful contributions.

The articles in this issue offer a number of important insights relevant to enhancing community engagement toward social change. For instance, Cattaneo et al. describe a social justice-oriented service-learning course and, using quantitative measures, advocate for a focus on the systemic nature of social problems and for critical consideration of identity and life experience to best understand students' responses to and engagement with the issues centered in the course. The authors highlight that changes in deficit and systems thinking about marginalized communities are not part of a single continuum for learners. Individuals can hold these beliefs at the same time, and each must be deconstructed as part of community service-learning's educational process.

Castillo-Montoya et al. utilize the framework of Latinx critical consciousness to examine student reflections, allowing for a better understanding of how Latinx students are engaging in and with their class and grappling with issues of privilege, identity, and agency in their classroom context. The focus on critical consciousness of BIPOC students (and here a focus on Latinx subjectivities) is less common in the SLCE literature but a necessary direction for decentering whiteness and privilege within this literature space. The exclusion of BIPOC students can allow for the presumption that a minoritized group membership equates to a particular level or state of critical consciousness. Similarly, the common practice of relying on group comparisons of BIPOC students and White students may homogenize specific BIPOC groups and/or obscure understanding of within-group variation in the developmental profiles and needs of BIPOC students.

Yee et al.'s exploration of critical service-learning in an Asian American studies course reflects the goals and pathways desired via service-learning — that students see connections between their lives and identities and move to do work in and with communities that work toward social transformation. The authors use counternarratives and employ intersectionality and critical race theory in ways that highlight historically excluded narratives and offer new possibilities for imagining community in the service-learning practice and to leverage student leadership toward agentic understandings of social change.

Brewster et al.'s efforts intersect critical information literacy and critical service-learning aimed at increasing students' social justice learning. The researchers use a combination of student assignments and interviews to assess students' learning in five areas: view of service, view of others, view of group differences, understanding the problem, and taking action. These areas of assessment raise important questions for how social justice is understood and conveyed in service-learning experiences, as well as what kinds of experiences are integrated to develop students' understandings about these concepts. Their work argues for a more robust assessment of praxis to improve social justice teaching and learning.

Emerging from a multiyear partnership with residents of the Pine Ridge Reservation, Carwile describes a "place-engaged" critical community engagement experience that works to bridge academics and Indigenous epistemologies. This experience centers recent calls to challenge implicit/explicit settler colonialism in communityengaged work (Santiago-Ortiz, 2019; Yep \& Mitchell, 2017) through student reflections and Lakota voices. Car- 
wile concludes that critical community engagement requires invitation to the place where learning happens and a disruption to the dichotomies of service and the continuing legacies of settler colonialism by "listening and following the lead of our partners in deciding what we should do and what we should know and hear.”

Rhinesmith et al. assert that in order for universities' community service-learning efforts to be justice work, they must include and center community partners' views and definitions of the ethical obligations of university and student partners, beyond formal institutional ethics and compliance-focused guidelines and policies. Drawing on interview data from community organization staff leaders, the authors demonstrate how the ethical domains of respect, beneficence, and justice should inform community engagement efforts as well as how those efforts have fallen short of these expectations. In advocating for a relational approach to ethical service-learning, they offer seven strategies for community-university partnerships that can support servicelearning toward social justice.

Along with indicators from these authors' works that service-learning can positively impact learner attitudes (which presumably impact subsequent behaviors) and approaches of engaging with marginalized communities toward action and change, there remain critical challenges and limitations in the field. Some challenges are embedded in service-learning frameworks themselves-how service-learning goals are conceptualized, structured, and taken up in university settings.

It is still often the case that social justice is framed as an individual-level endeavor, and there can be an overemphasis on individual process relative to justice goals. Attention must be given to what types of changes can be implemented so that social justice within service-learning education is reconceptualized as realized tangible goals toward social transformation, including changing material conditions of injustice and impacting community members' lived experiences.

Another ongoing challenge for the field of service-learning toward advancing social justice is the diversity of the field itself; the demographic backgrounds of those engaged in service-learning teaching and scholarshipboth faculty and students - tend to reflect their higher education institutions, predominantly White and middle class or more socioeconomically advantaged. In contrast, the communities being engaged are more likely to be made up of racially and ethnically minoritized groups and those from less advantaged socioeconomic backgrounds. The participation of White people in service-learning efforts to achieve social justice is important; for example, their understanding of the nature of White racial privilege and willingness to act on this knowledge is important to dismantling inequitable systems. However, to move higher education community engagement forward, it is also critical for whiteness to be decentered-by including (and proactively recruiting) BIPOC individuals at college/university levels as teachers and learners; infusing learning and cultural frameworks that focus on BIPOC student identity development; offering opportunities for BIPOC students to work within their own communities; and implementing strategies for community engagement and action informed by histories and traditions of social activism among BIPOC communities.

One of the biggest challenges is perhaps what we're asking of service-learning in higher education. SLCE is work tasked with multiple responsibilities: to contribute to the amelioration of social concerns in our communities through service, to prepare and encourage students to be active participants in democratic society, to deepen 
students' knowledge and understanding of the social applications of the academic subjects they are studying, to develop their awareness and recognition of their social position and the ways that social identities shape people's lives, among other areas of action and intra- and interpersonal processes. This practice is often seen as holding possibilities for transformation ... for the individual, for higher education institutions, and for our communities. Many of us are inspired to community-engaged work because of our hope or expectation that these multiple transformative aims can be realized.

But community engagement is not a panacea. Indeed, "to hope that community service might function as a panacea for the complex problems of contemporary communities . . is misguided" (Neururer \& Rhoads, 1998, p. 326). While potentially misguided, our work is not only to hope for an engagement praxis that is transformative but to develop and implement community engagement experiences that center social justice with aims toward more just futures.

Centering social justice in the scholarship of community engagement is a call to both practice and research. It is important that we aim for a community engagement praxis that centers social justice-that seeks to bring more just conditions to our communities and more just futures for the people in those communities. It is also important and necessary to center social justice in our scholarship - to consider the places and possibilities for justice in community-engaged work and to reveal the successful and substandard outcomes resulting from higher education's efforts to implement engagement work both for student and community development.

\section{References}

Allen, J., Almukhtar, S., Aufrichtig, A., Barnard, A., Bloch, M., Cahalan, S., Cai, W., Calderone, J., Collins, K., Conlen, M., Cook, L., Gianordoli, G., Harmon, A., Harris, R., Hassan, A., Huang, J., Issawi, D., Ivory, D., Lai, K. K. R. . . Yoon, J. (2021, May 5). Coronavirus in the US: Latest map and case count. The New York Times. https://www.nytimes.com/interactive/2021/us/covid-cases.html

Feeding America. (2021, March 9). One year later Feeding America asks America "H ow many facing hunger is too many?" https://www.feedingamerica.org/about-us/press-room/one-year-later.

Neururer, J., \& Rhoads, R. A. (1998). Community service: Panacea, paradox, or potentiation. Journal of College Student Development, 39(4), 321-330.

Santiago-Ortiz, A. (2019). From critical to decolonizing service-learning: Limits and possibilities of social justice-based approaches to community service-learning. Michigan Journal of Community Service Learning, 25(1), 43-54.

Yep, K. S., \& Mitchell, T. D. (2017). Decolonizing community engagement: Reimagining service learning through an ethnic studies lens. In C. Dolgon, T. D. Mitchell, \& T. K. Eatman (Eds.), The Cambridge handbook of service learning and community engagement (pp. 294-303). Cambridge University Press.

Yurcaba, J. (2021, March 11). As anti-trans violence surges, advocates demand policy reform. NBC News. https:// www.nbcnews.com/feature/nbc-out/anti-trans-violence-surges-advocates-demand-policy-reform-n1260485. 